\title{
Editorial
}

\section{COVID-19, Spiritual Support and Reflective Practice}

\author{
Lindsay B. Carey ${ }^{1}$ \\ Public Health Palliative Care Unit, La Trobe University, Melbourne, Australia \\ Email: lindsay.carey@latrobe.edu.au
}

\section{Introduction}

Three important areas are covered in this issue of HSCC: (i) COVID-19, (ii) spiritual support and (iii) reflective practice - all fundamental to the future of chaplaincy. It is important to note that various formal research methodologies (whether quantitative or qualitative) are utilized across all three areas in this issue, and all are indicative of the changing nature of chaplaincy increasing its evidence-based practice.

Indeed, the emphasis on evidenced-based practice within chaplaincy has become considerable since the turn of the twenty-first century. This is particularly important given the previous humanistic models (i.e. biomedical, bio-psychological, bio-psychosocial), which have mostly (whether deliberately or subconsciously) avoided or opposed the inclusion of religious or spiritual care within health and social care contexts due to the lack of empirical evidence. This century seems to be advancing with an increased recognition of the need for a more truly holistic approach to health and well-being; namely, the utilization of the bio-psychosocial-spiritual model of care (Sulmasy, 2002), which intentionally encourages religion and spirituality research, and the encompassing of those from any faith and those with non-religious belief systems.

The bio-psychosocial-spiritual model is also increasingly important for ensuring that there is appropriate religious/spiritual care for future

1. Rev. Dr. Lindsay Carey is HSCC Editor-in-Chief and Senior Lecturer/Research Fellow at the Public Health Palliative Care Unit, La Trobe University, Melbourne, Australia. 
generations. Despite those who try to argue that religiosity/spirituality is declining, in fact, it is quite the opposite. Admittedly, while some countries (e.g. the United Kingdom) are experiencing a downturn in religious affiliation, nevertheless, "the religious impulse has proven resilient" (Nolan \& MacLaren, 2021) and looks as though it will continue to be so, despite the most anti-religious efforts of some who deliberately strive to undermine religious values and under-value the altruistic commitments according to which religious people act. Perhaps it will come as a surprise to some that, globally, religiosity/spirituality is actually on the rise (PRC, 2017), ${ }^{2}$ and, as some clinicians are now recognizing, "religious values in clinical practice are here to stay” (Kørup et al., 2020). As Kørup and colleagues go on to state,

contrary to Nietzsche's statement, ${ }^{3}$ at least in clinical practice, God is not dead. Rather it seems the value-neutral physician is and remains dead. Government, health-care suppliers and tone-setting medical associations worldwide, should accept this reality and work toward a future where the utilization of personal values is encompassed in the entire career chain of medical professionals, from the curriculum in medical schools to clinical training of professionals. (Kørup et al., 2020, p. 191)

Each of the articles contained in this issue of HSCC effectively challenges tokenistic models of care, in order to emphasize the importance of including religion, spirituality, pastoral care and/or the role of chaplains, who usually work in tandem with other disciplines (Carey, Swinton \& Grossoehme, 2018).

\section{COVID-19}

As a follow on from the HSCC special issue on COVID-19 (Carey, Swift \& Burton, 2020), this issue considers the same pandemic. Irrespective of the efficacy of vaccinations, it is undeniable that COVID-19 has ravaged many parts of the world, and has been the primary focus of attention for governments, academic researchers, clinicians, nurses and allied health practitioners (including chaplains). It has previously been noted that over 80,000 refereed published journal articles were recorded by the SCOPUS Elsevier database regarding COVID-19 during 2020 - the top ten researching

2. The Pew Research Centre estimates that the number of people affiliated to a religion will increase to 2.3 billion by 2060 , with Islam becoming the most dominant religion post-2060.

3. In his text The gay science, Nietzsche tried to argue that "God is dead, God remains dead. And we have killed him" (Nietzsche, 1882). 


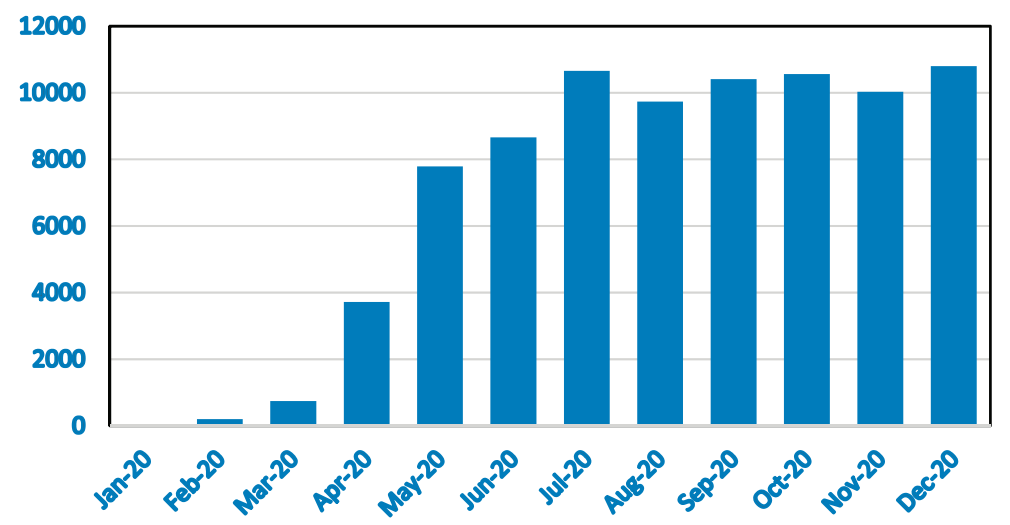

\section{Figure 1}

COVID-19 journal publications published January-December 2020 (SCOPUS, N=83,137) Source: Goyal, R. D. (2021). COVID-19 publication statistics - SCOPUS. Amsterdam: Elsevier (statistical analysis inquiry initiated by Dr. Lindsay Carey, Palliative Care Unit, La Trobe University, January 2021).

nations being the United States, China, the United Kingdom, Italy, India, Spain, Canada, Germany, France and Australia, respectively (Carey, 2021). As a recognized peer review journal, HSCC has thus far contributed 15 COVID-19 publications to the total number. Internationally, journal publications related to COVID-19 during 2020 averaged (overall) 6,000 articles per month, and 10,000 articles per month from July onwards (see Figure 1).

The first article related to COVID-19 in this issue is written by Ian Stirling (2020). He presents the incredible work of chaplains with regard to the formation of the spiritual care team specifically set up as part of the NHS Louisa Jordan hospital COVID-19 mission (Glasgow, Scotland). As the author summarizes about this contemplative inquiry, "It is a snapshot in time and offers a rare glimpse into the humanity and vulnerability of the spiritual care team as they face this far from normal situation". The second article referencing COVID-19 by Brandstötter, Kundt and Paal (2021) presents an Austrian perspective about nursing students in Salzburg from 2018-2020 with regard to their spiritual well-being, attitude, involvement, perceptions and competencies. This research is valuable when considering the development of nursing spiritual care competencies and the educational gap in the curriculum that needs to be bridged, in order for future nurses to be capable and confident with spiritual care. 


\section{Spiritual Support}

A number of articles in this issue consider the spiritual support provided through a variety of allied healthcare disciplines. The first is by Miles and associates (2020), who consider the spiritual support provided by chaplains for those having experienced advance heart failure (AHF). This is the first feasibility randomized controlled (RCT) trial to ascertain the clinical and cost effectiveness of a spiritual intervention in AHF patients. The findings about conducting RCTs in this specialist area are intriguing and should be read by all interested in spirituality research. The second article by Wood and co-workers (2021), is a UK-NHS qualitative study that considers the perspectives of various users of mental health spiritual and pastoral care chaplaincy services. The majority affirmed the role of chaplains and supported extending their service.

Florence Gelo (2021) acknowledges the important role of art therapy as an allied health treatment (Byrne \& Levey, 2018). Gelo utilizes a narrative arts-based approach to care for a patient in palliative care. Her article demonstrates how an art image can serve as a stimulus to help those at the end of life identify and integrate aspects of self that might otherwise remain unexpressed and unresolved. Another similar area of spiritual support is that of music therapy - an ever increasing and important area of allied health support (O'Callaghan \& Edwards, 2018). Notarangelo (2020) argues that music therapy supports the health and flourishing of individuals and groups, but including spirituality into music therapy has many challenges - particularly with regard to community-building projects.

Finally, in this area of spiritual support, there is also "mankind's best friend" - the dog. More specifically, "Poppy Jingles" (Carlyle \& Watson, 2020). Some people have a fear of, or are repulsed by canines, but Poppy Jingles seems to provide a pet therapy that is appreciated by the clinical staff and patients alike, which is particularly valuable when personal and organizational stress runs high.

\section{Reflective Practice}

Last, but by no means least, we consider reflective practice. Suzanne Bunniss presents us with a two-part series about making courageous conversations. First, she explains the design and evaluation of the "Values Based Reflective Practice" (VBRP ${ }^{\star}$ ) training for health care professionals in Scotland (Bunniss 2021a). The VBRP ${ }^{\circledR}$ initiative is designed to help health and social care staff (including chaplains) have courageous conversations about the relationship between who they are and what they do at work, with the 
stated aim of helping staff to reclaim a sense of meaning and purpose in their professional lives, and reawaken the memory of why they chose to work in a caring vocation - an issue which one could argue is particularly important given workforce exhaustion created by a lack of resources within healthcare systems forever trying to become more efficient, but which can compromise effectiveness that ultimately challenges patient and staff health and well-being.

Second, Bunniss (2021b) explores the practical use and impact of VBRP ${ }^{\circledast}$ on individual professionals. Qualitative evidence is presented from ten semi-structured interviews with a range of healthcare professionals who used the $\mathrm{VBRP}^{\circledast}$ programme. The thematic results discuss staff experiences and learning given the $\mathrm{VBRP}^{\oplus}$ training, the impact upon their professional practice, the impact on those with leadership responsibility, and strategies for improving $\mathrm{VBRP}^{\circledR}$ for the benefit of future healthcare staff.

The final reflective practice article by Hennequin (2020) describes two evaluation frameworks to assist with improving spiritual care best practice, including governance, credentialling and quality improvement processes. The results of her cross-sectional descriptive study involving spiritual care managers in Australia found that the frameworks were effective tools for auditing, benchmarking and improving quality in spiritual care departments across multiple healthcare services, and were useful for supporting spiritual care departments in undertaking continuous improvement initiatives. More can be read about these frameworks in Hennequin's (2020) chapter in the open access (free to download) e-text book by Peng-Keller and Neuhold (2020), "Charting spiritual care: The emerging role of chaplaincy records in global health care". I also recommend reading the brief critique of Hennequin's (2020) work by Livia Wey-Meier (2020), which follows Hennequin's chapter and is also freely available to download.

\section{Epilogue}

In the next issue, we would like to revisit COVID-19, to hear of your reflective experiences acknowledging the loss/grief throughout 2020 and 2021, but also how chaplaincy can help people and institutions to re-normalize: "Chaplaincy and COVID-19: Past, present and future". Previous and new authors are encouraged to write submissions on this topic, as well as about other topics pertinent to their ministry. Please note that HSCC is transitioning to a new updated online platform, and that all articles are now published online via "advance access" as soon as possible prior to being allocated to hard copy publication. 


\section{Acknowledgments}

The Editor-in-Chief would like to thank his Co-Editors (in alphabetical order by surname) Rev. Meg Burton, Rev. Dr. Duncan McLaren, Rev. Dr. Daniel Nuzum, Dr. Piret Paal, Dr. Linda Ross and Rev. Dr. Chris Swift for their contributions to Health and Social Care Chaplaincy during 2021. Appreciation is also expressed to Rev. Dr. Mark Newitt (HSCC Book Review Editor) and to the HSCC Editorial Board members for undertaking manuscript reviews.

\section{References}

Brandstötter, C., Kundt, F. S., \& Paal, P. (2021). Spiritual well-being, attitude, involvement, perceptions and competencies: Measuring the self-perception of nursing students during 2018, 2019 and the first wave of COVID-19 in 2020. Health and Social Care Chaplaincy, 9(2). https://doi.org/10.1558/hscc.18468

Bunniss, S. (2020a). Making courageous conversation in healthcare (part I): Designing and evaluating Values Based Reflective Practice ${ }^{\bullet}$ training for healthcare professionals in Scotland. Health and Social Care Chaplaincy, 9(2). https://journals.equinoxpub.com/ HSCC/article/viewArticle/40701

Bunniss, S. (2020b). Making courageous conversation in healthcare (part II): Exploring the impact of Values Based Reflective Practice on professional practice. Health and Social Care Chaplaincy, 9(2). https://journals.equinoxpub.com/HSCC/article/viewArticle/ 40702

Byrne, L., \& Levey, L. (2018). Art therapy and spiritual care. In L. B. Carey \& B. A. Mathisen (Eds.), Spiritual care for allied health practice: A person-centered approach (chapter 7, pp. 137-161). London: Jessica Kingsley Publishers. https://intl.jkp.com/aus/spiritual-carefor-allied-health-practice.html

Carey, L. B. (2021). COVID-19, nursing, pediatrics and measuring religion and health. Journal of Religion and Health, 60(1), 1-4. https://doi.org/10.1007/s10943-020-01174-6

Carey, L. B., Swift, C., \& Burton, M. (2020). COVID-19: Multinational perspectives of providing chaplaincy, pastoral, and spiritual care. Health and Social Care Chaplaincy, 8(2), 133-142. https://doi.org/10.1558/hscc.41973

Carey, L. B., Swinton, J., \& Grossoehme, D. (2018). Chaplaincy and spiritual care. In L. B. Carey \& B. A. Mathisen (Eds.), Spiritual care for allied health practice: A person-centered approach. London: Jessica Kingsley Publishers. https://intl.jkp.com/aus/spiritual-carefor-allied-health-practice.html

Carlyle, D., \& Watson, K. (2020). "Dog" is "God" spelled backward: "Poppy Jingles", the staff well-being spaniel. Health and Social Care Chaplaincy, 9(2). https://journals.equinoxpub.com/HSCC/article/view/41120

Gelo, F. (2021). A weary old warrior: An arts-based case study in palliative care. Health and Social Care Chaplaincy, 9(2). https://journals.equinoxpub.com/HSCC/article/ viewArticle/42237

Goyal, R. D. (2021). COVID-19 publication statistics - SCOPUS. Amsterdam: Elsevier.

Hennequin, C. M. (2021). Evaluating the effectiveness of frameworks benchmarking for quality spiritual care in Victoria, Australia. Health and Social Care Chaplaincy, 9(2). https://journals.equinoxpub.com/HSCC/article/view/40326

Hennequin, C. (2020). Charting and documenting spiritual care in health services: Victoria, 
Australia. In S. Peng-Keller \& D. Neuhold (Eds.), Charting spiritual care: The emerging role of chaplaincy records in global health care (pp. 79-91). Cham: Springer International Publishing. https://doi.org/10.1007/978-3-030-47070-8

Kørup, A. K., Søndergaard, J., Christensen, R. D., Nielsen, C. T., Lucchetti, G., Ramakrishnan, P., ... \& Hvidt, N. C. (2020). Religious values in clinical practice are here to stay. Journal of Religion and Health, 59(1), 188-194. https://link.springer.com/article/10.1007/ s10943-018-0715-y

Nietzsche, F. (1882). The gay science [original title: Die fröhliche Wissenschaft]. London: Penguin Books.

Nolan, S., \& MacLaren, D. (2021). Religious, spiritual, pastoral ... and secular? Where next for chaplaincy? Health and Social Care Chaplaincy, 9(1), 1-10. https://doi.org/10.1558/ hscc. 42735

Notarangelo, A. (2020). Ecological awareness in practice: Spirituality, community health, and the possibilities of music therapy. Health and Social Care Chaplaincy, 9(2). https:// journals.equinoxpub.com/HSCC/article/viewArticle/41473

O'Callaghan, C., \& Edwards, J. (2018). Music therapy and spiritual care. In L. B. Carey \& B. A. Mathisen (Eds), Spiritual care for allied health practice: A person-centered approach (chapter 8, pp. 162-182). London: Jessica Kingsley Publishers. https://intl.jkp.com/aus/ spiritual-care-for-allied-health-practice.html

Peng-Keller, S., \& Neuhold, D. (2020). Charting spiritual care: The emerging role of chaplaincy records in global health care. New York: Springer. https://doi.org/10.1007/ 978-3-030-47070-8

PRC (2017). The changing global religions landscape. Washington: Pew Research Centre. https://www.pewforum.org/2017/04/05/the-changing-global-religious-landscape/

Sulmasy, D. P. (2002). A biopsychosocial-spiritual model for the care of patients at the end of life. The Gerontologist, 42(suppl_3), 24-33. https://doi.org/10.1093/geront/42.suppl_3.24

Wey-Meier, L. (2020). Commentary: Charting and documenting spiritual care in health services: Victoria, Australia. In S. Peng-Keller \& D. Neuhold (Eds.), Charting spiritual care: The emerging role of chaplaincy records in global health care (pp. 92-94). Cham: Springer International Publishing. https://doi.org/10.1007/978-3-030-47070-8

Wood, E., Ross, S., Raffay, J., \& Todd, A. (2020). Service user views of mental health spiritual and pastoral care chaplaincy Services. Health and Social Care Chaplaincy, 9(2). https:// journals.equinoxpub.com/HSCC/article/viewArticle/40947 